\title{
DESAFIOS DA FORMAÇÃO UNIVERSITÁRIA: PENSAR A PRÁTICA SOB ONTOLOGIA MATERIALISTA ${ }^{1}$
}

Elza Margarida de Mendonça Peixoto ${ }^{2}$

\section{RESUMO}

Perguntando pelo sentido da prática que deve orientar a formação científica de trabalhadores de educação, o artigo traz a defesa da posição de que a prática préprofissional na formação universitária de trabalhadores da educação deve estar orientada pela ontologia e gnosiologia materialista e dialética, relatando-se estudo teórico que orienta proposta curricular em andamento na Universidade Federal da Bahia (Salvador) dirigida ao aperfeiçoamento e à transformação da formação universitária de professores de educação física.

Palavras-Chave: Trabalho; Formação; Trabalhadores da Educação; Prática; Ontologia; Materialismo

\section{UNIVERSITY TRAINING CHALLENGES: THINK ABOUT THE PRACTICE UNDER ONTOLOGY MATERIALISTIC}

\begin{abstract}
Asking about the meaning of practice that must guide the scientific training education workers, the article brings the defense position that the pre-professional practice in the university training of workers in education must be guided by materialist and dialectics ontology and gnosiology, showing theoretical study that guides curriculum proposal in progress at the Federal University of Bahia (Salvador) steered to the improvement and to the transformation of university education of physical education teachers.
\end{abstract}

Key words: Job; Education; Education Workers ; Practice; Ontology; Materialism.

\section{A pergunta pelo sentido da prática na formação dos trabalhadores da educação}

É certo que há quem viva - ou pareça viver - sem perguntar. Acatando irreflectidamente ${ }^{3}$, circunscrevendo a paciência a espera e resignação (sem atentar na sua constitutiva dimensão de trabalho), a vida é passada e sofrida, alegre ou tristemente, com monotonia entediada ou irrequietude elétrica, sem, no entanto, jamais ser posta em questão, isto é, sem na realidade jamais se ver interrogada.

É certo que há quem multiplique perguntas, mas, em verdade, não interrogue. Interrogar o real não é simplesmente justapor a evidências intocadas indagações exteriores. Interrogar é solicitar o real, por dentro e para dentro, fazendo o seu interior, o que nele positiva e potencialmente se alberga, revelar-se e mostrar-se. A interrogação é, na raiz, um trabalhar dialético das evidências (Barata-Moura, 1996, p. 105). 
Tratamos aqui dos nexos entre o fazer dos trabalhadores da educação (o seu trabalho) e os processos mais adequados para a sua formação. Exatamente, tratamos da prática pré-profissional na formação universitária de trabalhadores da educação. Dispomonos a pensar esta prática pré-profissional impulsionados pela própria demanda da prática profissional. Pensar a prática tomando a prática como critério de verdade. Pensar a prática. De que falamos?

\section{Pensar "aquilo que é" em ontologia materialista}

Se coloca como tarefa para os que fazem a formação de professores exercitar o pensar a prática pré-profissional impulsionados pela própria demanda da prática profissional. Mas o pensar a prática porta possibilidade de transformação, de movimento, de mudança?? Em que o pensar a prática contribui para aprimorar a formação dos professores?

Em artigo de 1994, o filósofo José Barata-Moura, defende que "pensar aquilo que é" é a tarefa e o problema da filosofia, apresentando-nos importantes esclarecimentos sobre o pensar e o pensar filosófico:

O pensar - inclusivamente, o pensar filosófico -, sem ser a instância materialmente determinante, é, no entanto, uma ingrediência constitutiva do trabalho, que lhe modela rasgos decisivos no registo da qualidade.

A mediação pensante enriquece as determinações da operação laborativa, alarga o horizonte de consciência que a acompanha, estimula uma atenção ao leque de possíveis em que é chamada a materializar-se (Barata-Moura, 1994, p. 77).

E mais:

O pensar filosófico define o quadro subjectivo de uma mediação reflexiva do acontecer, onde a crítica assoma como vigilância incontornável, onde a fundamentação se ergue como demanda a empreender, onde a prática se desenha como prolongamento exigente (BARATA-MOURA, 1994, p. 78).

Em outro texto de 1996, diz-nos:

(...) a demanda da especificidade do pensar filosófico é, porventura, susceptível de encontrar-se na conjugação, entre outros, de quatro vectores principais:

- exercício permanente de vigilância crítica,

- procura radical de fundamentação,

- posição esclarecida de um horizonte de problemas,

- identificação e trabalho do leque de possíveis que cada existência, tecida e entretecida de contradições, adiante de si pro-jecta.

Se a crítica nos remete para a dialeticidade intrínseca do real, na multiplicidade concreta e deveniente das suas determinações, a demanda radical do fundamento encaminha-nos para a sondagem dos supostos que sustentam e estruturam a imediatez aparecente, o esclarecimento da dimensão problemática possibilita-nos $\mathrm{o}$ acesso a plataformas de consideração que historicamente definem o encontro mais adequado dos respondimentos, e a exploração, pensada e pensante, dos possíveis estende-nos diante o vector do futuro que como feituro na e pela nossa prática ssoma (BARATA-MOURA, 1996, p. 107).

O pensar a prática pré-profissional impulsionados pela própria demanda da prática profissional nos desafia como "mediação reflexiva do acontecer", como crítica 
vigilante incontornável, com exigência da fundamentação, em que a substância e a interpretação estão em disputa, como "ingrediência constitutiva do trabalho", como enriquecer das "determinações da operação laborativa" própria da prática profissional.

Defendendo a centralidade do pensar "aquilo que é" como tarefa da filosofia, Barata-Moura, demarcando posição no debate, esclarece:

Reivindicar para a filosofia a missão de pensar "aquilo que é" significa recentrá-la e desenvolvê-la no marco de uma atenção fundamental à ontologia. (...)

Trata-se (...) de descortinar, e de prosseguir com consequência, a dimensão radical e radicante do ser - na sua materialidade, na sua dialeticidade, na multiplicidade de planos em que historicamente se estrutura (Barata-Moura, 1991, p. 80).

A tarefa e o problema dos que formam professores é contribuir no pensar "aquilo que é" a "prática profissional" dos professores. A partir desta atenção fundamental à ontologia - tarefa e problema dos filósofos, tarefa e problema, estamos defendendo aqui, também dos que formam professores - trata-se de "descortinar" e perseguir a dimensão radical e radicante do ser professor. Trata-se "de fertilizar o viver pela filosofia, isto é, de lhe acrescentar as mais-valias de uma habitação mais densa do mundo e da história". Trata-se de "uma compreensão racional do acontecer" que "não dispensa (...) uma crítica (igualmente racional) do existente que desemboca em comportamentos transformadores de reconfiguração". Uma demanda pela razão que "não é apenas teoricamente compreensiva" mas também "prática dialética" (BARATA-MOURA, 1994, p. 79).

Pensar "aquilo que é" a "prática profissional dos professores", para pensar a "prática pré-profissional", demanda reconhecer as coordenadas de uma ontologia materialista.

Ainda com Barata-Moura, pensar "aquilo que é" em perspectiva materialista envolve reconhecer que "o ser nunca é mera clausura numa imediatez uniforme":

$\mathrm{O}$ ser ${ }^{4}$ advém materialmente como tecido de historicidade, as suas identidades estão perpassadas de diferença e de contradição; o existente sempre projecta adiante de si um leque determinado de possíveis.

A negatividade pulsa no corpo e na textura do ser; mesmo quando conduzida e protagonizada por agentes sociais, porque é sempre situada e decorre em condições determinadas nunca vem a resolver-se em mera excrescência ou adjunção exterior.

É neste espaço dinâmico e deveniente que a racionalidade, humana e historicamente, se inscreve, como procura e esforço de informação/transformação do existente (BARATA-MOURA, 1994, p. $80)$.

Entretanto, não é pela idealização bem-intencionada de “"“deveres ser” transcendentes" que a transformação do existente pode se dar. Pelo contrário, é "pelo trabalho das contradições existentes, e das possibilidades reais, que a negação se opera, que o desenvolvimento se prossegue, que o futuro se reconfigura".

Para além da "consagração acomodada do existente" e o "visionarismo utópico, de intenção grandiloquente e de sofisticado efeito, na realidade, contraproducente",

A alternativa é outra; tem um caminho bem mais apertado e de navegação difícil. A dimensão revolucionária prática do pensar e do viver passa pelo trabalho consequentemente transformador da contraditoriedade do existente. 
É ai que a filosofia e o pensar, em geral, são chamados a exercitar, mobilizando decerto entre os seus recursos a engenhosidade criadora da imaginação, a sua indispensável tarefa de crítica, de fundamentação, de esclarecimento dos problemas e dos possíveis. (...)

Como Marx sublinhava, na carta a Ruge (...): "nós não queremos antecipar dogmaticamente o mundo, mas apenas queremos encontrar, a partir da crítica do mundo velho" - de uma crítica não só teórica, mas também determinantemente prática - "o mundo novo" (Barata-Moura, 1994, p. 80).

\section{O trabalho em ontologia materialista e dialética}

Posicionando-nos na disputa pela direção da formação de professores momentaneamente isentando-nos da tarefa de listar as posições em disputa - tomemos em Saviani (2008, pp 11-22), a precisão do fazer próprio do trabalho educativo; os fundamentos da prática profissional, cuja prática pré-profissional desejamos antecipar nos processos de formação universitária de professores.

Em Sobre a natureza e a especificidade da educação, argumenta Saviani que "a compreensão da natureza da educação passa pela compreensão da natureza humana" (Saviani, 2008, p.11). Os homens, para existir, necessitam "produzir continuamente sua existência", ou seja, necessitam continuamente, adequar a natureza às suas necessidades, isto é, transformar a natureza orientados por uma antecipação mental da finalidade da ação e do plano que orienta a ação.

Saviani está, aqui, retomando Marx e Engels quando afirmam, apresentando os supostos da Concepção Materialista e dialética:

Em relação aos alemães, que se consideram isentos de pressupostos, devemos começar por constatar o primeiro pressuposto de toda a existência humana e também, portanto, de toda a história, a saber, o pressuposto de que os homens têm de estar em condições de viver para poder "fazer história". Mas, para viver, precisa-se, antes de tudo, de comida, bebida, moradia, vestimenta e algumas coisas mais. O primeiro ato histórico é, pois, a produção dos meios para a satisfação dessas necessidades, a produção da própria vida material, e este é, sem dúvida, um ato histórico, uma condição fundamental de toda a história, que ainda hoje, assim como a milênios, tem de ser cumprida diariamente, a cada hora, simplesmente, para manter os homens vivos (MARX, 2007, p. 32$33)$.

Fazer história supõe a existência de indivíduos humanos vivos, supõe humanos produzindo sua existência. Antecede a capacidade de pensar, a necessidade de produzir-se vivo, de produzir as condições para produzir-se vivo (MARX, 2007, p. 32-34). Ora, este ato de produzir-se vivo é o ato fundante do ser do homem, é sua atividade vital, aquela sem a qual não há vida humana (MARX, 1989, pp. 146-164;. P. 155). Esta atividade vital é o trabalho cuja preciosa síntese explicativa encontramos no capítulo V de "O Capital", é "um processo de que participam o homem e a natureza, processo em que o ser humano com sua própria ação, impulsiona, regula e controla seu intercâmbio material com a natureza". Neste processo, o ser humano "Defronta-se com a natureza como uma de suas forças", "põe em movimento as forças naturais do seu corpo (...) a fim de apropriar-se dos recursos da natureza imprimindo-lhes forma útil à vida humana", e, ao fazê-lo, atua "sobre 
a natureza externa modificando-a, ao mesmo tempo (em que) modifica sua própria natureza" (MARX, 2008, p. 211-212).

Este impor (à natureza) forma útil à vida humana ocorre determinado pelo fato de que o homem "figura na mente sua construção antes de transformá-la em realidade" de modo a que "no fim do processo de trabalho aparece um resultado que já existia antes idealmente na imaginação do trabalhador" (MARX, 2008, p. 211-212). Esta ideação prévia só é possível, Marx explicita, pelo fato de o homem ter apropriado - em um longo processo evolutivo cuja marca foi a contínua experimentação - as potencialidades da natureza produzindo meios de trabalho e a si mesmo como capaz de produzi-los e manuseá-los.

Aqui está o que é próprio do ser genérico do homem ${ }^{5}$. O ser do homem (ou a ontologia humana, ou "o que é aquilo que é" o ser do homem) é determinado pelo modo como realiza o trabalho de produção da sua existência em determinadas condições históricas, fazendo história, mas de acordo com as condições que lhes foram legadas pelo passado, entre estas, as potencialidades materiais reais da natureza, o estágio do desenvolvimento do conhecimento dos homens sobre estas potencialidades, o estágio do desenvolvimento dos instrumentos que a partir destas potencialidades da natureza, os homens conseguem produzir, as relações de produção que é necessário estabelecer para potencializar o estágio de desenvolvimento destes instrumentos.

A tese de Marx é que a ontologia humana, o ser do homem em sua materialidade, só pode ser apreendido no observar da forma como se realiza a sua atividade vital, a atividade sem a qual não há vida, a atividade contínua de produção da vida que configura a história da existência humana. Esta atividade vital, entretanto, não pode ser apreendida no fragmento, no isolamento desta ou daquela atividade em si, desta ou daquela forma de trabalho. É na história, nas relações de produção de uma dada época estabelecidas sobre um determinado estágio de desenvolvimento das forças produtivas, que a ontologia do ser homem explicita-se materialmente ${ }^{6}$.

\section{O trabalho educativo em ontologia materialista e dialética}

Em Sobre a natureza e a especificidade da educação, Saviani apanha este fundamento da Concepção Materialista e Dialética, para explicar "aquilo que é" a educação: um "fenômeno próprio dos seres humanos"; "uma exigência do e para o processo de trabalho", uma vez que os homens têm de transmitir às futuras gerações os conhecimentos que adquiriram neste ato contínuo de atuar sobre a natureza apreendendo suas possibilidades e subordinando-a às suas necessidades.

É assim que “(...) o que não é garantido pela natureza tem que ser produzido historicamente pelos homens, e aí se incluem os próprios homens". Tal como Marx, Saviani recorda que "(...) a natureza humana não é dada ao homem, mas é por ele produzida sobre a base da natureza biofísica". A educação é uma exigência do e para o processo de trabalho por que "(...) o trabalho educativo é o ato de produzir, direta e intencionalmente, em cada indivíduo singular, a humanidade que é produzida histórica e coletivamente pelo conjunto dos homens" (Saviani, 2008, p. 13).

Noutras palavras, a ontologia humana tem em sua raiz o trabalho como atividade vital, e a educação, nas mais variadas formas que se desenvolveu ao longo da história da humanidade, é aquilo que permite passar às futuras gerações "aquilo que é" o ser do homem, o modo como o homem produz a sua existência em cada conjuntura. Os conhecimentos necessários para reconhecer os elementos dessa produção da existência em cada formação social. 
Definido "aquilo que é" o trabalho educativo, o "objeto da educação" vai, então, dizer respeito, "de um lado, à identificação dos elementos culturais que precisam ser assimilados pelos indivíduos da espécie humana para que eles se tornem humanos" e, "de outro lado e concomitantemente, à descoberta das formas mais adequadas para atingir este objetivo" (Saviani, 2008, p. 13). A escola vai ser definida como "uma instituição cujo papel consiste na socialização do saber sistematizado". Mas, o autor apressa-se a assinalar, que "não se trata (...) de qualquer tipo de saber", mas do saber científico, pois

\begin{abstract}
(...) a opinião, o conhecimento que produz palpites, não justifica a existência da escola. Do mesmo modo, a sabedoria baseada na experiência de vida dispensa e até mesmo desdenha a experiência escolar (...). É a exigência de apropriação do conhecimento sistematizado por parte das novas gerações que torna necessária a existência da escola. A escola existe, pois, para propiciar a aquisição dos instrumentos que possibilitam o acesso ao saber elaborado (ciência), bem como o próprio acesso aos rudimentos desse saber (SAVIANI, D. 2008, p. 13-15).
\end{abstract}

A tese fundante desta que foi nomeada por Saviani como Pedagogia históricocrítica, atravessa a obra de Marx e consolida-se na Psicologia Histórico-Social: o homem não nasce homem, se torna homem em um processo que envolve a continua realização pela humanidade da produção da existência pelo trabalho, que, para não partir sempre do mesmo lugar, exige da humanidade o trabalho educativo de apropriação do acumulado pelos homens: a cultura.

\title{
Pensar a Prática em ontologia materialista e dialética
}

Iniciamos este texto propondo tratar dos nexos entre o fazer dos trabalhadores da educação (o seu trabalho) e os processos mais adequados para a sua formação. Definimos a demanda pelo pensar aquilo que é como critério para o pensar a especificidade do fazer dos trabalhadores da educação.

À luz da pergunta por "aquilo que é", buscamos apreender "aquilo que é" próprio do fazer dos trabalhadores da educação para pensar a prática pré-profissional na formação universitária de trabalhadores da educação. Dispuse-mo-nos a pensar esta prática préprofissional impulsionados pela própria demanda da prática profissional. Pensar a prática tomando a prática como critério de verdade. materialista?

Resta-nos perguntar: mas o que é aquilo que é a prática em ontologia

Mais uma vez, Barata-Moura no ajuda a reconhecer as "ontologias da práxis" em busca de uma "radicação ontológica da prática" orientada por uma ontologia materialista (BARATA-MOURA, 2000, pp. 13-32). Precisamente, pergunta-se o autor: "como pensar a prática num horizonte ontológico materialista"? Para nós, a questão fundante se avizinha: pensada a prática num horizonte ontológico materialista, quais pistas se delineiam para pensar a prática pré-profissional neste mesmo horizonte?

O autor principia por destacar que entenderá "ontologias em geral", como aquelas "doutrinas ou concepções que aceitam a pertinência de questionar acerca de "aquilo que é" (...) e ensaiam para este quesito respondimentos". Pontua que "Estamos perante uma ontologia quando o esforço da inquirição visa, em última análise, apurar o que haja de entender-se por "aquilo que é"”, (BARATA-MOURA, 2000, p. 15). Precisa:

O que conta - nos termos desta aclaração sumária, mas fontal - é o papel inaugural, instituinte, constituinte, de que essa dimensão práxica 
(determine-se ela em si mesma como se determinar) se reveste, ou em que é investida.

O problema que permanece, e desafia, é o da compreensão do lugar do acto e da feitura no horizonte plástico do ser (BARATA-MOURA, 2000, p. 16).

Trata-se de investigar como diferentes matizes pensam o "lugar do acto e da feitura no horizonte plástico do ser", e, neste investigar, o reconhecer de uma "ideia" (que vai fazendo o seu caminho) de que "haja uma acção a sustentar todo o plano do conhecimento - ou de que o conhecer não acabe por resolver-se em mera contemplação passiva, mas se desvende como atividade posicional e instituinte" (BARATA-MOURA, 2000, p. 17).

Esclarece que foi a "crítica do primado da consciência representativa, em geral" e, acrescenta, "como muitas outras circunstâncias decorrentes do próprio desenvolvimento da historicidade do ser" - que "levou diferentes correntes filosóficas a debruçarem-se e a in-sistir sobre uma outra modalidade constitutiva da atividade humana: a prática" (BARATA-MOURA, 2000, p. 18). Trata-se, justamente, do precisar dos supostos destas diferentes correntes, reconhecendo sua posição idealista e materialista no respondimento à pergunta por "aquilo que é" a prática. Aprofunda:

Ao lado, e para além, de concepções consequentemente materialistas da prática, como a de Marx, por exemplo - em que o homem é encarado na sua concreção material (e não apenas como pura cabeça criticante, descorporizada e des-socializada), em que "a consciência" é constitutivamente "o ser consciente", e em que a materialidade do ser, enquanto materialidade, não é feita depender de qualquer Setzung "práxica" (ainda que o trabalho e a prática social desempenhem um papel fundamental na configuração do mundo e da história) - ao lado e para além das concepções deste teor, dizia, desenvolvem-se, no entanto, também muitas outras abordagens que, apesar de similitudes terminológicas flagrantes, e até das genealogias invocadas, acabam por revestir um alcance distinto, na medida em que, realmente, não partilham os seus supostos.

Apresentando-se, por vezes, como interpretações genuínas, ou como a revelação derradeira do "segredo" do pensamento de Marx, muitas destas doutrinas não formam, porventura, senão um ramalhete sortido de críticas idealistas do primado (idealista) da representação, efectuadas em nome da práxis (Barata-Moura, 2000, p. 20).

Demarcando-se destas posições - que vai detidamente analisar, mas cuja análise não dispomos de espaço para transcrever aqui - Barata-Moura vai assinalar como traço definidor dos "idealismos da prática" a posição da "“"práxis" - carregada ora de traços intimistas ou mais comunicativos, ora de rasgos mais pragmáticos e manipuladores - (...) como a dimensão por excelência, ou como a única dimensão autêntica do ser" (BARATAMOURA, 2000, p. 26).

Por sua vez, o "materialismo consequente", põe como suposto, "na determinação do alcance dessa prática", que ela é "uma atividade material de transformação efectiva da realidade objectiva"; que ela é "uma categoria constitutiva do ser humano". Considerada "no seu sentido forte de categoria filosófica", a prática "modela, afeiçoa e transforma a materialidade do real (a partir e de dentro dele); não o põe na sua materialidade" (BARATA-MOURA, 2000, pp. 26-27).

De um ponto de vista materialista, o prisma de abordagem não pode investir a prática (a consciência, a linguagem, etc) em condição de 
possibilidade ante-posta ou simultaneamente posta à materialidade, em geral. A prática não é o factor instituinte da materialidade enquanto tal; transformando-a, e dando-lhe figura, é ingrediência humana, histórica, material, da própria mediação do ser.

É de dentro da materialidade do ser (que como humanos integramos) que a prática se destaca e intervem como feitura exercitada da sua própria textura (BARATA-MOURA, 2000, p. 31).

\section{Desafios da formação universitária:}

Cabe agora apontar o caminho do respondimento às questões que levantamos: qual o sentido da prática que deve orientar a formação científica de trabalhadores da educação? O pensar a prática porta possibilidade de transformação, de movimento, de mudança?? Porta possibilidade de "transformação material"? Em que o pensar a prática contribui para aprimorar a formação dos professores?

A pergunta por "aquilo que é" a prática rigorosamente levada a cabo por BarataMoura nos leva a um leque de ontologias da prática a cuja investigação os que formam professores devem dedicar-se para descortinar as ideologias por traz das práticas de Ensino e dos Estágios supervisionados. Redimensionar a prática pré-profissional à luz de uma ontologia materialista demanda uma avaliação rigorosa dos limites da prática de ensino e do estágio supervisionado.

No sentido forte de "atividade material de transformação", Barata-Moura reconhece a acção política ${ }^{7}$, a experimentação ${ }^{8}$ e o trabalho ${ }^{9}$ como "figuras particulares da prática" (BARATA-MOURA, 1994, p. 87-88, p. 90-91).

Reconhecemos na prática pré-profissional possibilidades, quando a formação considera, rigorosamente:

(a) o estágio de desenvolvimento das forças produtivas e das relações de produção das formações sociais e do modo de produção da vida em que desenvolve-se a prática profissional - o trabalho pedagógico - dos trabalhadores da educação, em uma crítica que busca "pôr o emaranhado dos processos, recheados de contradições, na articulada concreção deveniente que formam" (BARATA-MOURA, 2013, p. 14);

(b) quando a experimentação está assentada, não em uma caricatura do trabalho educativo, mas em uma investigação que associa o apanhar das tendências conjunturais, com o estágio de desenvolvimento daquilo que já é conhecido sobre o fazer profissional dos trabalhadores da educação;

(c) por fim, quando o formador que conduz a prática pré-profissional não se isenta da tarefa de analisar minuciosamente a correlação de forças em que se inscrevem (i) as disputas pela direção da formação dos professores e (ii) a disputa pela direção do trabalho educativo que se faz em uma sociedade de classes e em um modo de produção que tem como eixo a felicidade isolada do indivíduo e a acumulação privada.

A partir destes requisitos teóricos que possibilitam reconhecer uma perspectiva materialista e dialética na prática pré-profissional, a formação de professores pode ultrapassar a perspectiva das ontologias idealistas da prática. 


\section{Referências}

BARATA-MOURA, J. "Pensar aquilo que é" tarefa e problema da filosofia. Vértice, março/abril, N. 59, pp 77-81, 1994.

BARATA-MOURA, J. Prática - Para uma aclaração do seu sentido como categoria filosófica. Caderno I. Lisboa: Colibri, 1994.

BARATA-MOURA, J. Que é filosofar? Vértice, dezembro, N. 75, pp 104-108, 1996.

BARATA-MOURA, J. Marx e a cientificidade do saber. In: Barata-Moura, J. Materialismo e Subjetividade: estudos em torno de Marx. Lisboa: Avante!, 1997.

BARATA-MOURA, J. Das “ontologias da Práxis" a uma radicação ontológica da prática. Praxis - Seminário Ibérico de Filosofia. Lisboa, Portugal, p. 13-32, 2000.

MARX, K. O capital. Livro I, Volume 1. Rio de Janeiro: Civilização Brasileira, 2008.

MARX, K. O capital. Livro I, Volume 1. Rio de Janeiro: Bertrand Brasil: 1989.

MARX, K. O trabalho alienado. Fernandes, F. (Org.) Marx \& Engels: História. São Paulo: Ática, 1998.

MARX, K. Contribuição à crítica da economia política. São Paulo: Martins Fontes, 1987.

MARX, K.; Engels, F. A ideologia alemã. São Paulo: Boitempo, 2007.

PEIXOTO, E. M. de M. Pensar Ciência, Verdade e Prática sob ontologia materialista: subsídios à formação de professores. Anais do XII Congresso Nacional de Educação, Curitiba, PR, Brasil, p. 29724-29741, outubro, 2015.

SAVIANI, D. Sobre a natureza e a especificidade da educação. In Saviani, D. Pedagogia histórico-crítica: primeiras aproximações. Campinas, SP: Autores Associados, 2008.

\section{Notas:}

${ }^{1}$ Este artigo resulta de Pesquisa de Pós-Doc desenvolvida na Faculdade de Letras, Departamento de Filosofia, Universidade de Lisboa. A pesquisa foi financiada pelo Programa de Estágio Pós-Doutoral no Exterior. Número do processo: BEX 1571/14-1

${ }^{2}$ Professora da Faculdade de Educação - Universidade Federal da Bahia. Editora do Periódico Germinal: Marxismo e Educação em Debate. Líder do Grupo de Estudos e Pesquisas Marxismo e Políticas de Trabalho e Educação.

${ }^{3} \mathrm{O}$ acordo hortográfico não encontra unanimidade entre os portugueses. Assinalando este debate, as citações que faço neste artigo respeitam a grafia dos textos originais.

${ }^{4}$ Determinantemente, o filosofar é um cultivo re-flexivo do ser: do ser que somos, do ser que em conjunto mediamos, da história do ser que através de nós se vai realizando (Barata-Moura, 1996, p. 107).

${ }^{5}$ Conforme a terceira determinação do trabalho alienado:

O homem é um ser genérico, não só na medida em que teórica e praticamente faz do gênero, tanto do seu próprio quanto do das demais coisas, o seu objeto, mas também - e isto é apenas uma outra expressão para a mesma coisa - na medida em que se relaciona consigo mesmo como com o gênero vivo, presente, na medida em que se relaciona consigo mesmo como com um ser universal e por isto livre.

Tanto no homem quanto no animal a vida do gênero consiste fisicamente em que o homem (tal como o animal) vive da natureza inorgânica, e quanto mais universal o homem é do que o animal, tanto mais universal é o âmbito da natureza inorgânica da qual vive. Assim como plantas, animais, pedras, ar luz, etc., formam teoricamente uma parte da consciência humana, em parte como objetos da Ciência Natural e em parte como objetos da arte - a sua natureza inorgânica espiritual, meios de vida espirituais que ele tem primeiro que preparar para a fruição e a digestão -, assim também formam praticamente uma parte da vida 
humana. Fisicamente o homem vive só destes produtos da natureza, quer apareçam na forma de alimento, calefação, vestuário, moradia, etc. Na prática a universalidade do homem aparece precisamente na universalidade que faz da natureza inteira o seu corpo inorgânico, tanto na medida em que ela é 1 . Um meio de vida imediato, quanto na medida em que é [2.] a matéria, o objeto e o instrumento da sua atividade vital. A natureza é o corpo inorgânico do homem, a sabe, a natureza na medida em que ela mesma não é corpo humano. O homem vive da natureza, significa: a natureza é o seu corpo, com o qual tem que permanecer em constante processo para não morrer. Que a vida física e mental do homem está interligada com a natureza não tem outro sentido senão que a natureza está interligada consigo mesma, pois o homem é uma parte da natureza (Marx, 1989, pp. 154-155).

${ }^{6}$ A tecnologia revela o modo de proceder do homem para com a natureza, o processo imediato de produção de sua vida e assim elucida as condições de sua vida social e as concepções mentais que delas decorrem (MARX, 1989, nota 89, p. 425).

$\mathrm{Na}$ síntese de 1857: [...] na produção social da sua existência, os homens estabelecem relações determinadas, necessárias, independentes de sua vontade, relações de produção que correspondem a um determinado grau de desenvolvimento das forças produtivas materiais. O conjunto destas relações de produçãoo constitui a estrutura econômica da sociedade, a base concreta sobre a qual se eleva uma superestrutura jurídica e política e a qual correspondem determinadas formas de consciência social (MARX, 1977, p. 24).

7 "No universo da materialidade social do ser, a acção política concertada devem um privilegiado instrumento prático de operar a sua transformação". Citando Engels: "Ideias nunca podem levar para além (...) de um velho estado do mundo. Ideias, sobretudo, não podem executar nada (...). Para o executar das ideias são precisos os homens, que empregam um poder (...) prático" (BARATA-MOURA, 1994, p. 98. Ver também nota 26 na mesma página).

${ }^{8}$ Alerta que "experimentação" ("uma atividade prática, de transformação ou feitura efectiva, envolve a realização prática, operativa de um teste: é constitutivamente produção, e não mera exibição de algo") não é "experiência" ("atividade teórica empírica, de acolhimento numa consciência de algo que sensivelmente se nos mostra ou impõe”) (BARATA-MOURA, 1994, p. 99).

9 “Com o trabalho, a prática assoma na sua constitutiva dimensão estrutural, e estruturante, da produção e reprodução do viver pelas e nas sociedades humanas” (BARATA-MOURA, 1994, p. 101).

Recebido: março-16 Aprovado: setembro-16 